\title{
Behavioral tagging of extinction learning
}

\author{
Jociane de Carvalho Myskiw ${ }^{1}$, Fernando Benetti, and Iván Izquierdo ${ }^{1}$ \\ National institute of Translational Neuroscience, National Research Council of Brazil, and Memory Center, Brain Institute, Pontifical Catholic University of Rio \\ Grande do Sul, 90610-000 Porto Alegre, RS, Brazil
}

Contributed by Ivan Izquierdo, December 3, 2012 (sent for review November 19, 2012)

\begin{abstract}
Extinction of contextual fear in rats is enhanced by exposure to a novel environment at 1-2 $\mathrm{h}$ before or $1 \mathrm{~h}$ after extinction training. This effect is antagonized by administration of protein synthesis inhibitors anisomycin and rapamycin into the hippocampus, but not into the amygdala, immediately after either novelty or extinction training, as well as by the gene expression blocker 5,6-dichloro-1-beta-D-ribofuranosylbenzimidazole administered after novelty training, but not after extinction training. Thus, this effect can be attributed to a mechanism similar to synaptic tagging, through which long-term potentiation can be enhanced by other long-term potentiations or by exposure to a novel environment in a protein synthesis-dependent fashion. Extinction learning produces a tag at the appropriate synapses, whereas novelty learning causes the synthesis of plasticity-related proteins that are captured by the tag, strengthening the synapses that generated this tag.
\end{abstract}

$\mathbf{F}_{\mathrm{p}}^{\mathrm{e}}$ ear memories are essential for survival; however, their expression out of context or in inadequate instances of daily life can lead to anxiety or phobias (1) or to the serious and incapacitating condition known as posttraumatic stress disorder (PTSD) (1-4). Thus, it is desirable to extinguish fear memories when they are uncalled for (2), and to restrict their retrieval to appropriate circumstances $(2,3)$.

Extinction, the learned inhibition of retrieval (1-6), is widely used in the treatment of PTSD, often under the term "exposure therapy" (2-4). First described for alimentary learning (5), extinction involves not the erasure of original memories $(1,3,4,6)$, but merely the attenuation of responses to these memories (1-9). It relies on the activation of NMDA receptors in the hippocampus, basolateral amygdala (BLA), and ventromedial prefrontal cortex (4) and requires protein synthesis in these three structures shortly after its acquisition (7-9).

Given the wide use of extinction in psychotherapy, determining whether it is modulatable, like other forms of learning, is desirable. In recent work, we showed that extinction indeed can be modulated by several neurotransmitter systems acting on the hippocampus, BLA, or prefrontal cortex (4). Here we show that extinction also can be modulated by the hippocampal process known as synaptic tagging (10-19).

Frey and Morris $(10,11)$ and their collaborators (12-16) (see also ref. 17) have proposed a mechanism in which relatively weak "early" long-term potentiation (LTP) at hippocampal synapses lasting only a few minutes may "tag" these synapses with proteins synthesized ad hoc, allowing other proteins produced at other sets of synapses by other LTPs $(10-16)$ or by behaviors that require the hippocampus (16-19) to be captured by the tagged synapses, thereby strengthening their activity to a "long LTP" lasting hours or days (12-15). These proteins are referred to as plasticity-related proteins (PRPs) (10-17). This tagging mechanism also applies to, and has been reported in, hippocampal long-term depression (LTD), and "cross-tagging” between LTP and LTD, by which an LTP can turn a weak LTD into a strong LTD, has been described (16).

Long-lasting synaptic changes underlying long LTP or longterm memory (LTM) are widely believed to result from synaptic remodeling (20-23). Hippocampal long LTP has been repeatedly proposed (24-26) and actually was recently shown to underlie LTM formation of both aversive tasks (27-29) and object recognition learning (30). Thus, unsurprisingly, hippocampaldependent behavioral procedures that influence early LTP to become long LTP $(10-12,17)$ also may influence other hippocampal memories to make them stronger (10-12). This is the case for the effect of exposure to a novel environment on singletrial contextual fear conditioning (CFC) (15), inhibitory avoidance (19), object recognition (15), and spatial learning in a water maze (14). Exposure to a new environment triggers exploration, followed by habituation of the exploration (11-14). The enhancing effect of novelty on task retention has been interpreted as related to behavioral tagging by task retention, an expression used to denote the induction of synaptic tagging $(10,11)$ by behavioral manipulations $(15,18,19)$. Memories based mainly on the BLA or other brain areas are not influenced by tag-andcapture processes $(13,17)$.

The question of whether learning tasks can influence one another has been sporadically investigated sporadically over the past 3 decades (30-36). Exposure to a novel environment has been reported to cause retrograde amnesia of inhibitory avoidance when presented posttraining (32) and also to enhance retrieval of many memories when presented before retention testing (3336). These two effects are unrelated to synaptic tagging or to the capture of PRPs $(30,31,33)$.

Extinction requires glutamatergic NMDA receptor-dependent mechanisms in the hippocampus and other brain areas at the time of consolidation (4), followed by hippocampal ribosomal (37) and nonribosomal $(38,39)$ protein synthesis. Although several studies have suggested that memory consolidation of extinction learning relies on hippocampal LTP (1-6), the possibility exists that it may depend on the mechanistically related LTD (1-3). LTD is also initiated by NMDA receptors, is transformed by protein synthesis from an early brief form into a late long-lasting form, and generates and undergoes the effects of tagging $(16,40)$ (see also ref. 41).

In the present work, we studied whether extinction can produce behavioral tagging and whether it can be enhanced by novelty, presumably through PRPs (10-17), for capture by the tags, as occurs with LTP and with the various types of learning mentioned above. Novelty, as used here and in related experiments on behavioral tagging, refers to exposure to an open field (OF) $(15,18,19)$ or a holeboard (12), the exploration of which causes habituation learning and engenders hippocampal biochemical changes (42-44) that usually lead to protein synthesis.

\section{Results}

Extinction of Contextual Fear. Rats were trained in a CFC task $(4,43)$ and $24 \mathrm{~h}$ later were subjected to an extinction training session without reinforcement. At $30 \mathrm{~min}$ or $24 \mathrm{~h}$ after this training session, the rats were subjected to a test session involving short-term memory (STM) and LTM of extinction (4)

Author contributions: J.d.C.M. and I.I. designed research; J.d.C.M. and F.B. performed research; J.d.C.M. analyzed data; and J.d.C.M. and I.I. wrote the paper.

The authors declare no conflict of interest.

${ }^{1}$ To whom correspondence may be addressed. E-mail: jociane_carvalho@hotmail.com or izquier@terra.com.br.

This article contains supporting information online at www.pnas.org/lookup/suppl/doi:10. 1073/pnas.1220875110/-/DCSupplemental. 
(Fig. 1). Those two training test intervals are frequently used to evaluate the STM and LTM of various behaviors and of early LTP and long LTP $(13,44-47)$. The first retrieval session can be viewed as a training session of extinction learning given that it is carried out without reinforcement (4), and the second session can be viewed as a test session of extinction $(4,44)$. A CFC procedure involving three instead of two foot shocks and a shorter extinction training session (10 min instead of $20 \mathrm{~min}$ ) (4) was used to make extinction presumably weaker compared with that seen in other recent studies $(4,44)$.

Effect of Novelty (Exposure to an OF) on Extinction of Contextual Fear. The rats were exposed for $5 \mathrm{~min}$ to an $\mathrm{OF}$ at various intervals either before or after a weak extinction training session, or left unexposed (Fig. $2 A$ ). In the OF, the rats were allowed to explore freely, then gently withdrawn and replaced in their home cages $(15,18,19)$. Presentation of the OF for $1 \mathrm{~h}$ or $2 \mathrm{~h}$, but not for less than $1 \mathrm{~h}$ or for $3 \mathrm{~h}$ or longer, before the extinction session significantly enhanced extinction (Fig. $2 A$ and $B$ ). Exposure to the OF for $1 \mathrm{~h}$ but not for less or more than $1 \mathrm{~h}$ after extinction had a similar effect (Fig. $2 A$ ). These results are similar to those reported by others (19) on the effect of novelty on consolidation of CFC rather than its extinction.

The enhancing effect of exposure to the OF was not seen in rats that had been exposed before training, because when they were again exposed before extinction, it was familiar rather than novel (Fig. 2B). This is in agreement with the findings of Ballarini et al. (19) on the enhancing effect of a single exposure but not of a second exposure to an OF on acquisition of a spatial object recognition task. Spatial object recognition requires the hippocampus (47), probably because it correlates with CA1 LTP (29),

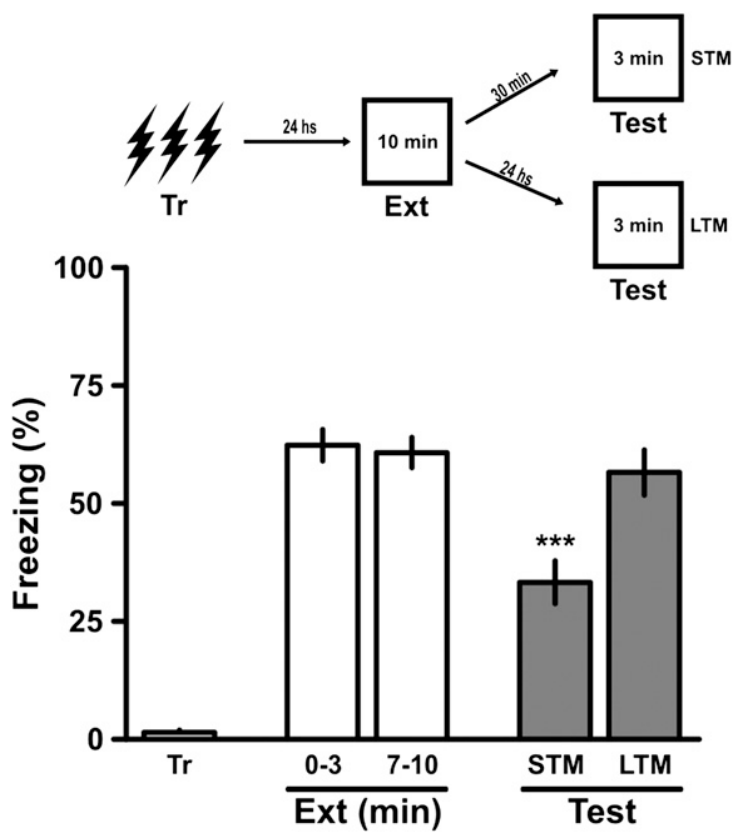

Fig. 1. Weak extinction training sessions can provide STM only. Rats were trained in a CFC task using three 2-s 0.5-mA scrambled foot shocks separated by 30 -s intervals in an enclosed environment. After $24 \mathrm{~h}$, they were exposed to a 10-min weak extinction training session with no stimulus in the same apparatus, then subjected to a 3-min test session 30 min later (STM test) or $24 \mathrm{~h}$ later (LTM test). The animals exhibited significant STM, but no LTM, of extinction learning in the test session. Data are presented as mean \pm SEM of the percentage of time spent freezing. ${ }^{* * *} P<0.001$ vs. the last $3 \mathrm{~min}$ of the extinction training session, Newman-Keuls test after one-way ANOVA; $n=$ 11 or 12 animals per group. (Upper) Schematic representation of the behavioral protocol used. like other tasks that are subject to enhancement by novelty (26-28), as apparently does spatial exploration of an OF as used here $(15,19,43)$.

Inhibitor of Gene Transcription and Two Different Inhibitors of Protein Synthesis in Hippocampus Hinder Behavioral Tagging of Extinction. The enhancing effect on extinction of exposure to a novel OF was fully blocked by the bilateral administration of anisomycin $(80 \mu \mathrm{g}$ per side), rapamycin (5 pg per side), or 5,6-dichloro-1-beta-D-ribofuranosylbenzimidazole (DRB; $8 \mathrm{ng}$ per side) into the dorsal CA1, but not into the BLA (Fig. S1), immediately after exposure to the $\mathrm{OF}$ (Fig. $3 A, C$, and $E$ ) or by anisomycin and rapamycin (Fig. $3 B$ and $F$ ), but not DRB (Fig. $3 D$ ), given immediately after the extinction training session. Thus, gene activation appears to be necessary for the production of the PRPs by the novelty, but not of the tag by the extinction training, whereas ribosomal and mammalian target of rapamycin (mTOR)-dependent protein synthesis seems to be important for both. Infusion of any of the three compounds into the BLA immediately after the novelty had no effect on the influence of the novelty on CFC extinction (Fig. S1). As in the preceding experiment, preexposure to the $\mathrm{OF}$ at $24 \mathrm{~h}$ before CFC training rendered it the exposure familiar rather than novel, and thus cancelled its effect on extinction performance; none of the drugs used had any effect on behavior (Fig. $3 A-C, E$, and $F$ ).

Thus, the effect of anisomycin on the behavioral tagging of extinction is similar to that reported for the behavioral tagging of aversive, spatial, or recognition learning $(14,15,18,19)$ and certainly like that seen in synaptic tagging (10-19). The effect of rapamycin on synaptic tagging has not yet been studied, and our finding that it blocked the effect of novelty on extinction suggests that it should be (Fig. $3 E$ and $F$ ). The localization of the mTOR system in nerve cells appears to be dendritic $(48,49)$, which in principle could lead to better synaptic specificity of the synthesized tag proteins and PRPs.

\section{Discussion}

In a recent article on the enhancement by novelty of spatial learning weakened by stress, Frey et al. (14) noted that "novelty processing can transform short-term into long-term memory. We propose that this memory-reinforcing effect of novelty could be explained by mechanisms outlined in the 'synaptic tagging hypothesis.' Initial STM is sustained by a transient plasticity change at activated synapses and sets synaptic tags. These tags are later able to capture and process the PRPs, which are required to transform a short-term synaptic change into a long-term one." This explanation may apply ipsis litteris to the interpretation of our present findings on the effect of novelty on extinction learning by tag-and-capture mechanisms, and also of course to the effect of novelty on hippocampal LTP (18) and on aversive, recognition, or spatial learning $(14,15,18,19,50)$.

Here we add the extinction of CFC to the list of memory types that may tag hippocampal synapses so that they can be enhanced by novelty. The addition of extinction to this list is an important argument in favor of the generality of the tagging process in learning $(10,11,13,14)$. Indeed, even though extinction is now widely regarded as one more form of learning $(1-4,6)$, it clearly is very different in terms of response requirement and other factors from all of the other learning situations to which the tagand-capture process has been applied so far $(1,14,15,18,19)$.

As is the case with the synaptic tagging of LTP (13), the effect of novelty on extinction can be attenuated by treatments administered into the hippocampus, but not by treatments administered into the BLA. In the present study, the enhancement of extinction by novelty was blocked by intrahippocampal DRB, anisomycin, or rapamycin given immediately after exposure to the OF, which would be expected to inhibit synthesis of PRPs, and also by anisomycin or rapamycin given after the extinction training session, which would be expected to block the 
A
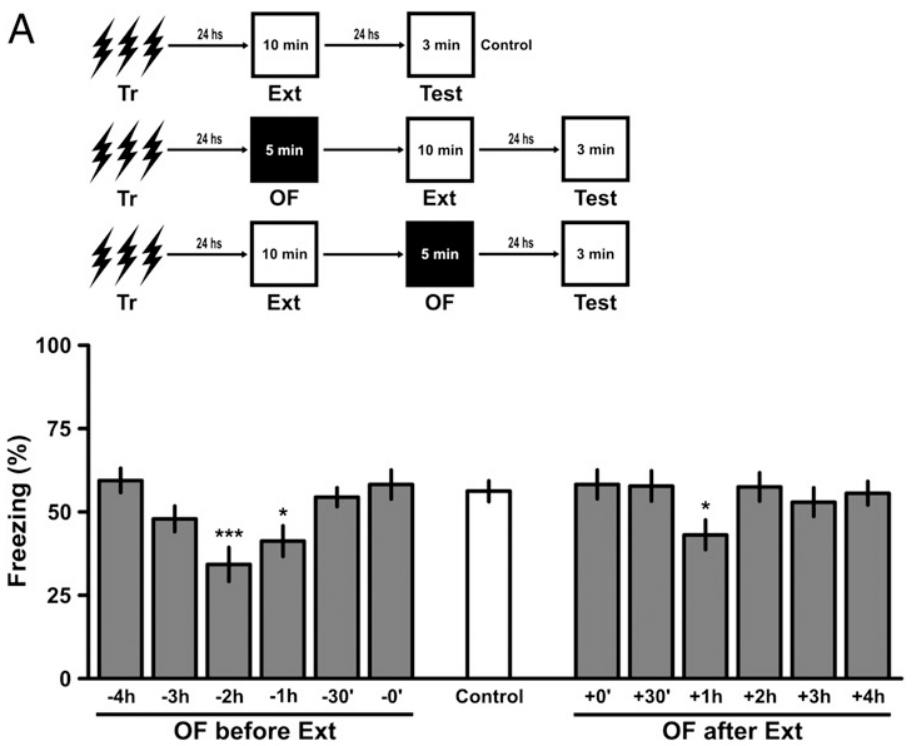

B
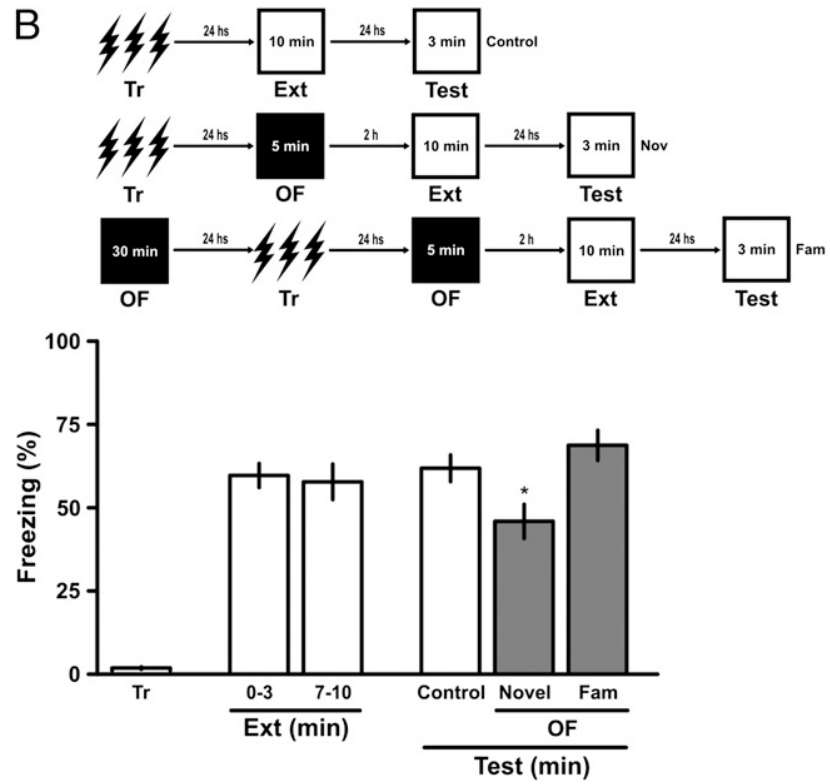

Fig. 2. Novelty presented before or after extinction training enhances CFC extinction. Animals were trained in a CFC task using three 2 -s $0.5 \mathrm{~mA}$ scrambled foot shocks separated by 30-s intervals in an enclosed environment. After $24 \mathrm{~h}$, they were randomly assigned to one of three groups: controls, which were exposed to just a weak extinction training session for $10 \mathrm{~min}$; groups exposed to a novel OF before extinction training ( $A$ and $B$ ), and groups exposed to a novel OF after extinction training $(A)$. In all cases the animals were submitted to a second or test extinction session $24 \mathrm{~h}$ after the first. Both in $A$ and in $B$, the upper graph schematizes the various training schedules. In $A$, the lower graph compares extinction test performance of animals not exposed to the OF (white bars) with that of animals exposed to the OF $0 \mathrm{~min}$ to $4 \mathrm{~h}$ before or 0 to $4 \mathrm{~h}$ after the extinction training session (grey bars). Note that when the novel OF was presented 1 or $2 \mathrm{~h}$ before training or $1 \mathrm{~h}$ after training it enhanced extinction; at other pre- and posttraining times it had no effect. In $B$ the lower graph shows extinction test performance in the first and in the last $3 \mathrm{~min}$ of the training session, and then the extinction test performance of animals exposed to either a novel or a familiar (Fam) OF $2 \mathrm{~h}$ before training. Again, the novel OF enhanced extinction test performance; exposure to a familiar OF had no effect. Data are presented as mean \pm SEM of the percentage of time spent freezing. ${ }^{\star} \mathrm{P}<0.05$ vs. control or vs. familiar OF session in Newman-Keuls test after ANOVA. $n=11$ or 12 animals per group.

production of a tag (10-18). This result suggests that both tagging and production of PRPs use regular ribosomal protein synthesis (38) as well as nonribosomal, probably dendritic, mTOR-mediated synthesis processes $(38,39)$, whereas tagging also requires gene expression.

The present work provides an important addition to the knowledge of modulation of extinction, which is important for the use of extinction in exposure therapy for $\operatorname{PTSD}(4,51)$. So far, extinction has been shown to be modulated both by the interpolation of a retrieval session and the resulting reconsolidation $(52,53)$, as well as by drugs that modify the action of modulatory neurotransmitters (4), including the serine analog D-cycloserine (54). Both reconsolidation (53) and D-cycloserine (54) have been used successfully in humans to enhance extinction (52). Here we add modulation through the interpolation of novelty, which should be easy to apply in humans as the simplest procedure with the fewest side effects.

Concerning the old question of whether one type of learning can influence other types $(30,31)$, our present results clearly support an affirmative response. The novelty of the OF, which leads to exploration and subsequent habituation, enhances the extinction of CFC. This effect can be explained by the tagging of hippocampal synapses by extinction and the production of hippocampal PRPs by the former, as has been suggested for LTP $(10,11)$, and for other types of learning $(12,14,15)$. In learning experiments, presenting one task too soon after another may cause mutual inhibition owing to mechanisms unrelated to tagging (32), which may explain why here, as in other behavioral observations, the timing of tagging processes is not continuous $(18,19)$ as it is in LTP experiments $(12-16)$. This point merits further investigation.

\section{Materials and Methods}

Mice. The animals used in these experiments were male Wistar rats ( 3 mo old, 300-320 g), purchased from Fundação Estadual de Produção e Pesquisa em Saúde do Rio Grande do Sul, our regular provider. The rats were housed five to a cage with water and food (Purina Laboratory Pellets) ad libitum, under a 12-h light/dark cycle (lights on at 7:00 AM). The temperature of the animal room was maintained at $22-24^{\circ} \mathrm{C}$. All procedures were in accordance with the National Institutes of Health's Guide for the Care and Use of Laboratory Animals and were approved by Pontifical Catholic University of Rio Grande do Sul's Bioethics Committee.

Surgery. At least $1 \mathrm{wk}$ after their arrival, some of the animals were implanted under anesthesia [75 mg/kg ketamine (König, Sao Paulo) plus $10 \mathrm{mg} / \mathrm{kg} /$ xylazine (Coopers, São Paulo)] with bilateral 27-g guide cannulae inserted $1.0 \mathrm{~mm}$ above the pyramidal cell layer of the dorsal CA1 area of the hippocampus ( $\mathrm{A},-4.2 ; \mathrm{L}, \pm 3.0 ; \mathrm{V},-2.0 \mathrm{~mm}$ ) or $1.0 \mathrm{~mm}$ above the BLA (A, -2.8 ; $\mathrm{L}, \pm 4.7 ; \mathrm{V},-7.5 \mathrm{~mm}$ ) (coordinates according to refs. 55 and 56 ). At $10 \mathrm{~d}$ after arrival or, in the animals that underwent implantation, 4-7 d after surgery, the rats were subjected to daily handling for 3 consecutive days and then trained in the CFC procedure between 8:00 and 11:00 AM (see below).

CFC Training. The training apparatus was a $35 \times 35 \times 35 \mathrm{~cm}$ aluminum box with a floor made of parallel caliber bronze bars spaced $0.8 \mathrm{~mm}$ between them. This training box was placed within another, larger box with soundproof walls to attenuate external sounds. The percentage of time that the rat spent freezing in the apparatus was measured automatically by a counter connected to photocells (Panlab).

On the day of training, the rat was allowed to explore the apparatus freely for $2 \mathrm{~min}$, after which it was given three 2-s, 0.5-mA scrambled foot shocks separated by 30-s intervals. The rat was left in the conditioning chamber for another $30 \mathrm{~s}$ and then placed back into its home cage. Basal freezing behavior was recorded before administration of the shocks. After $24 \mathrm{~h}$, the rat was exposed to the same apparatus without any stimulation for $10 \mathrm{~min}$ (extinction training session), then subjected to a retention test after $30 \mathrm{~min}$ (for STM) or after $24 \mathrm{~h}$ (for LTM). The percentage of time spent freezing (i.e., with no movement) was measured during all sessions. 


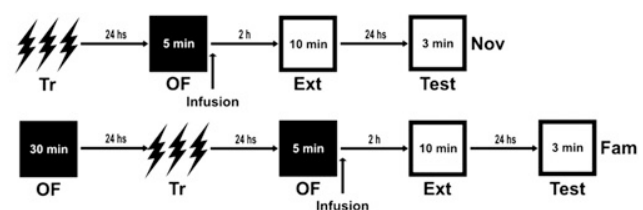

A

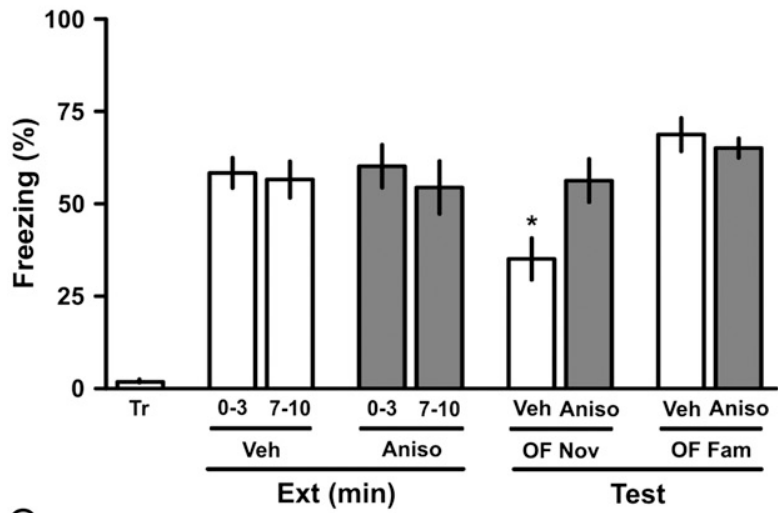

C

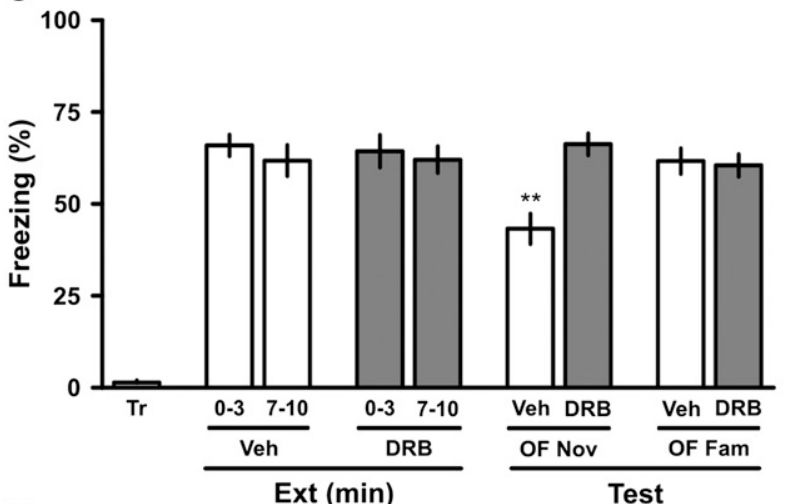

E

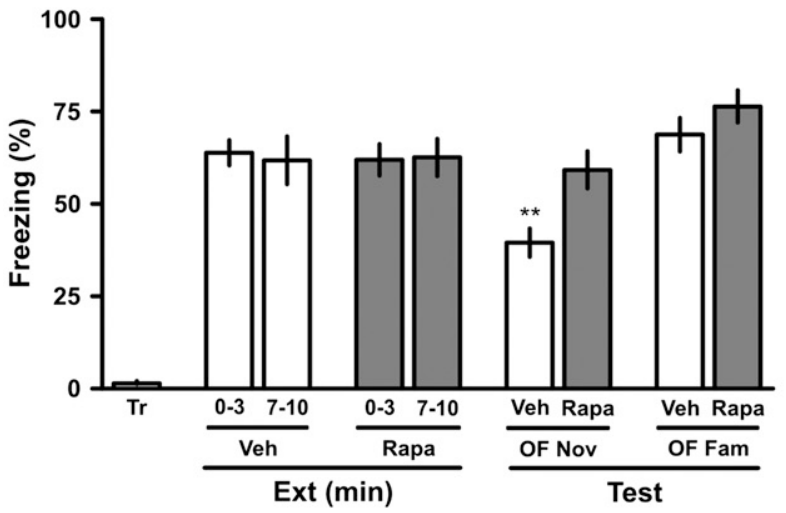

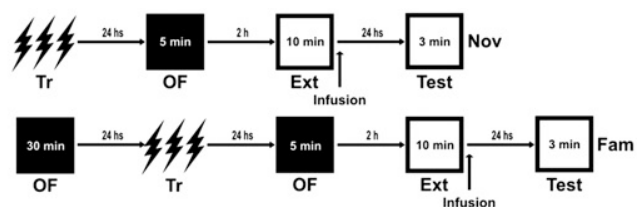

B

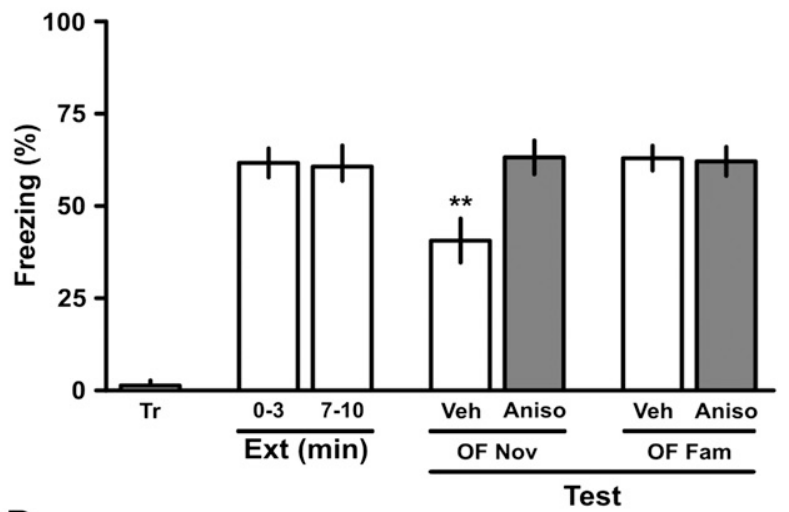

D

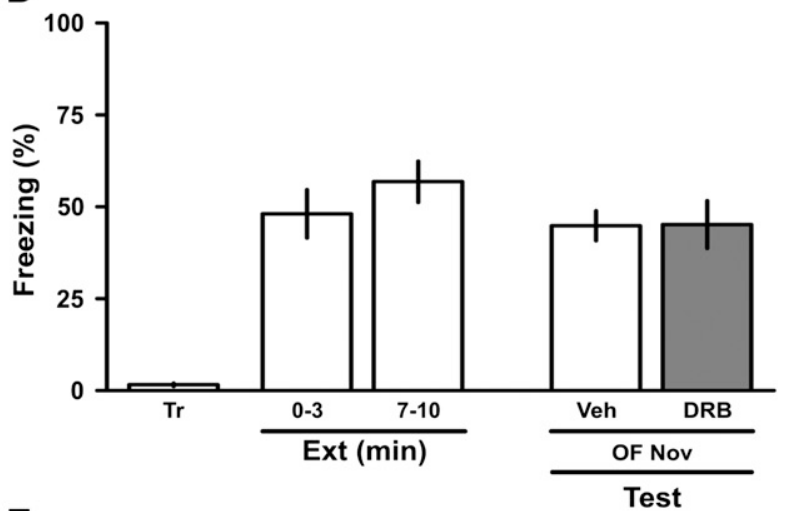

F

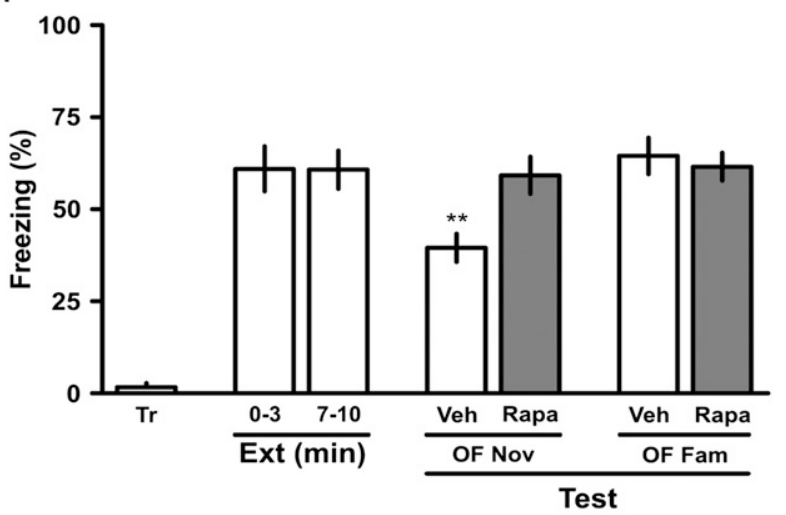

Fig. 3. Inhibition of hippocampal protein synthesis can prevent the benefit of contextual novelty. $(A$ and $B)$ Rats with infusion cannulae implanted in the CA1 region of the dorsal hippocampus were trained in a CFC task. After $24 \mathrm{~h}$, they received intra-CA1 infusions of either vehicle (Veh) or anisomycin (Aniso; $80 \mu \mathrm{g}$ per side) immediately after a 5-min exposure to a novel (Nov) or familiar (Fam) OF ( $A$ ) or immediately after a weak extinction training session (B). After another $24 \mathrm{~h}$, the animals were subjected to a 3-min retention test. ${ }^{*} P<0.05$ vs. all groups in test sessions, Newman-Keuls test after one-way ANOVA. ( $C$ and $D)$ Rats with infusion cannulae implanted in the CA1 region of the dorsal hippocampus were trained in a CFC task. After $24 \mathrm{~h}$, they received intra-CA1 infusions of either vehicle (Veh) or DRB (8 ng per side) immediately after a novel or familiar OF $(C)$ or immediately after a weak extinction training session $(D)$. After another $24 \mathrm{~h}$, the animals were subjected to a 3-min retention test. ${ }^{*}<0.05$ vs. all groups in test sessions, Newman-Keuls test after one-way ANOVA. ( $E$ and $F$ ) Rats with infusion cannulae implanted in the CA1 region of the dorsal hippocampus were trained in a CFC task. After $24 \mathrm{~h}$, they received intra-CA1 infusions of either vehicle or rapamycin (Rapa; 5 pg per side) immediately after a 5-min exposure to a novel or familiar OF ( $E$ ) or immediately after a weak extinction training session $(F)$. After another $24 \mathrm{~h}$, the animals were subjected to a 3-min retention test. ${ }^{\star} P<0.05$ vs. all groups in test sessions, Newman-Keuls test after one-way ANOVA. Data are presented as mean \pm SEM of the percentage of time spent freezing. $n=11$ or 12 animals per group. (Upper) Schematic representation of the behavioral protocol used. 
Exposure to an $\mathrm{OF}$. The testing apparatus was a $50 \times 50 \times 40 \mathrm{~cm}$ white-painted wooden box with a clear glass front wall. For a novel experience, the rat was exposed to the OF for $5 \mathrm{~min}$ at various times before or after the extinction training session. For a familiar experience, the rat was exposed to the OF for $30 \mathrm{~min}$ at $24 \mathrm{~h}$ before the extinction training session (19).

Drug Treatments. Less than $1 \mathrm{~min}$ after the end of the exposure to the OF or the extinction training session, the 30-gauge infusion cannula was fitted tightly into the guides so that its tip protruded $1.0 \mathrm{~mm}$ beyond the guide, first on one side and then on the other $(4,57)$. Drug or vehicle infusions were performed at a rate of $0.5 \mu \mathrm{L} / 30 \mathrm{~s}$. The infusion cannula was left in place for an additional $60 \mathrm{~s}$ to minimize backflow, then carefully withdrawn and placed on the other side, after which the foregoing procedure was repeated. The entire bilateral infusion procedure took approximately $90 \mathrm{~s}$. Drugs used included the inhibitor of ribosomal translation anisomycin ( $80 \mu \mathrm{g}$ per side) (38), the extraribosomal protein synthesis inhibitor rapamycin (5 pg per side) $(39,40)$, and the inhibitor of gene expression DRB (8 ng per side) (38). These doses have been reported to be effective (38-40). Rapamycin acts on an extraribosomal, presumably dendritic protein synthesis system that uses preexistent mRNA molecules and includes as a central component the protein kinase mTOR (39). At the doses used, these drugs affect the consolidation of avoidance conditioning and extinction when administered into rat hippocampus or amygdala, but have no effect on locomotion, exploration,

1. Orisini CA, Maren S (2012) Neural and cellular mechanisms of fear and extinction memory formation. Neurosci Biobehav Rev 36(7):773-802.

2. Sher L, Vilens A (2010) Neurobiology of Posttraumatic Stress Disorder (Nova, New York).

3. Milad MR, Quirk GJ (2012) Fear extinction as a model for translational neuroscience: Ten years of progress. Annu Rev Psychol 63:129-151.

4. Fiorenza NG, Rosa J, Izquierdo I, Myskiw JC (2012) Modulation of the extinction of two different fear-motivated tasks in three distinct brain areas. Behav Brain Res 232(1):210-216

5. Pavlov IP (1927) Conditioned Reflexes (Oxford Univ Press, London)

6. Bouton ME (2004) Context and behavioral processes in extinction. Learn Mem 11(5): 485-494.

7. Santini E, Ge H, Ren K, Peña de Ortiz S, Quirk GJ (2004) Consolidation of fear extinction requires protein synthesis in the medial prefrontal cortex. $J$ Neurosci 24(25): 5704-5710.

8. Vianna MR, Szapiro G, McGaugh JL, Medina JH, Izquierdo I (2001) Retrieval of memory for fear-motivated training initiates extinction requiring protein synthesis in the rat hippocampus. Proc Natl Acad Sci USA 98(21):12251-12254.

9. Vianna MR, Coitinho AS, Izquierdo I (2004) Role of the hippocampus and amygdala in the extinction of fear-motivated learning. Curr Neurovasc Res 1(1):55-60.

10. Frey U, Morris RG (1997) Synaptic tagging and long-term potentiation. Nature 385(6616): 533-536.

11. Frey S, Frey JU (2008) "Synaptic tagging" and "cross-tagging" and related associative reinforcement processes of functional plasticity as the cellular basis for memory formation. Prog Brain Res 169:117-143.

12. Uzakov S, Frey JU, Korz V (2005) Reinforcement of rat hippocampal LTP by holeboard training. Learn Mem 12(2):165-171.

13. Almaguer-Melian W, Bergado JA, Martínez-Martí L, Duany-Machado C, Frey JU (2010) Basolateral amygdala stimulation does not recruit LTP at depotentiated synapses. Physiol Behav 101(4):549-553.

14. Almaguer-Melian W, et al. (2012) Novelty exposure overcomes foot shock-induced spatial-memory impairment by processes of synaptic-tagging in rats. Proc Natl Acad Sci USA 109(3):953-958.

15. Moncada D, Ballarini F, Martinez MC, Frey JU, Viola H (2011) Identification of transmitter systems and learning tag molecules involved in behavioral tagging during memory formation. Proc Natl Acad Sci USA 108(31):12931-12936.

16. Sajikumar S, Frey JU (2004) Late-associativity, synaptic tagging, and the role of do pamine during LTP and LTD. Neurobiol Learn Mem 82(1):12-25.

17. Barco A, Lopez de Armentia M, Alarcon JM (2008) Synapse-specific stabilization of plasticity processes: The synaptic tagging and capture hypothesis revisited 10 years later. Neurosci Biobehav Rev 32(4):831-851.

18. Moncada D, Viola H (2007) Induction of long-term memory by exposure to novelty requires protein synthesis: Evidence for a behavioral tagging. I Neurosci 27(28) 7476-7481.

19. Ballarini F, Moncada D, Martinez MC, Alen N, Viola H (2009) Behavioral tagging is a general mechanism of long-term memory formation. Proc Natl Acad Sci USA 106(34) 14599-14604

20. Ramón y Cajal S (1893) New representation of the histological structure of the central nervous system. Arch Anat Physiol 17:319-428 German.

21. Greenough WT (2000) Morphological and molecular studies of synaptic memory mechanisms: Links to the fragile X mental retardation syndrome. Memory Consolidation: Essays in Honor of James L. McGaugh, eds Gold PE, Greenough WT (American Psychological Association, Washington, DC), pp 59-77.

22. Geinisman Y, Berry RW, Disterhoft JF, Power JM, Van der Zee EA (2001) Associative learning elicits the formation of multiple-synapse boutons. I Neurosci 21(15): 5568-5573. or performance in an elevated plus maze $(32,33,42)$. The drugs were dissolved in $2 \%$ DMSO, and $1.0 \mu \mathrm{L}$ per side was infused into the dorsal CA1 area of the hippocampus and $0.5 \mu \mathrm{L}$ per side was infused into the BLA.

Cannula Placement. Correct cannula placement was verified by infusion of a $4 \%$ (wt/vol) methylene blue solution over $30 \mathrm{~s}$ into the CA1 region of the dorsal hippocampus ( $1 \mu \mathrm{L}$ per side) or the BLA $(0.5 \mu \mathrm{L}$ per side) at the aforementioned coordinates at $2 \mathrm{~d}$ after the last behavioral experiment. The extent of the spread of the dye was considered to represent an estimate of the amount of drug infused. Cannula placement was considered correct when the spread was $\leq 1 \mathrm{~mm}$ from the intended infusion site (3); this occurred in $97 \%$ of the animals. As explained elsewhere (4), despite the uncertainty inherent in the unknown rate of solubility of the drugs used relative to methylene blue, this approach is an improvement over the mere determination of cannula tip location.

Statistics. Data were analyzed by one-way ANOVA followed by the NewmanKeuls or Dunnet test using Graphpad Prism software. $P<0.05$ was considered to indicate statistical significance.

ACKNOWLEDGMENTS. This work was supported by grants from the National Research Council of Brazil.

23. Morris RG, Anderson E, Lynch GS, Baudry M (1986) Selective impairment of learning and blockade of long-term potentiation by an N-methyl-D-aspartate receptor antagonist, AP5. Nature 319(6056):774-776.

24. Izquierdo I, et al. (2002) Memory retrieval and its lasting consequences. Neurotox Res 4(5-6):573-593.

25. Reymann KG, Frey JU (2007) The late maintenance of hippocampal LTP: requirements, phases, "synaptic tagging," "late-associativity," and implications. Neuropharmacol 52(1):24-40.

26. Izquierdo I, et al. (2006) Different molecular cascades in different sites of the brain control memory consolidation. Trends Neurosci 29(9):496-505

27. Gruart A, Muñoz MD, Delgado-García JM (2006) Involvement of the CA3-CA1 synapse in the acquisition of associative learning in behaving mice. J Neurosci 26(4): 1077-1087.

28. Whitlock JR, Heynen AJ, Shuler MG, Bear MF (2006) Learning induces long-term potentiation in the hippocampus. Science 313(5790):1093-1097.

29. Clarke JR, Cammarota M, Gruart A, Izquierdo I, Delgado-García JM (2010) Plastic modifications induced by object recognition memory processing. Proc Natl Acad Sci USA 107(6):2652-2657.

30. Netto CA, Dias RD, Izquierdo I (1985) Interaction between consecutive learnings: Inhibitory avoidance and habituation. Behav Neural Biol 44(3):515-520.

31. Izquierdo I, Netto CA (1985) Role of beta-endorphin in behavioral regulation. Ann NY Acad Sci 444:162-177.

32. Izquierdo I, Schröder N, Netto CA, Medina JH (1999) Novelty causes time-dependent retrograde amnesia for one-trial avoidance in rats through NMDA receptor- and CaMKII-dependent mechanisms in the hippocampus. Eur J Neurosci 11(9):3323-3328.

33. Izquierdo I, McGaugh JL (1985) Effect of a novel experience prior to training or testing on retention of an inhibitory avoidance response in mice: Involvement of an opioid system. Behav Neural Biol 44(2):228-238.

34. Izquierdo LA, Barros DM, Medina JH, Izquierdo I (2000) Novelty enhances retrieval of one-trial avoidance learning in rats 1 or 31 days after training unless the hippocampus is inactivated by different receptor antagonists and enzyme inhibitors. Behav Brain Res 117(1-2):215-220.

35. Izquierdo LA, Barros DM, Medina JH, Izquierdo I (2003) Exposure to novelty enhances retrieval of very remote memory in rats. Neurobiol Learn Mem 79(1):51-56.

36. Chaves ML, Izquierdo I (1986) Previous exposure to a novel experience enhances performance in two simple memory tests in humans. Braz J Med Biol Res 19(2): 211-219.

37. Zimmerman JM, Maren S (2010) NMDA receptor antagonism in the basolateral but not central amygdala blocks the extinction of Pavlovian fear conditioning in rats. Eur J Neurosci 31(9):1664-1670.

38. Igaz LM, Vianna MR, Medina JH, Izquierdo I (2002) Two time periods of hippocampal mRNA synthesis are required for memory consolidation of fear-motivated learning. $J$ Neurosci 22(15):6781-6789.

39. Myskiw JC, et al. (2008) On the participation of mTOR in recognition memory. Neurobiol Learn Mem 89(3):338-351.

40. Slipczuk L, et al. (2009) BDNF activates mTOR to regulate GluR1 expression required for memory formation. PLOS ONE 4(6):e6007.

41. Parvez S, Ramachandran B, Frey JU (2010) Functional differences between and across different regions of the apical branch of hippocampal CA1 dendrites with respect to long-term depression induction and synaptic cross-tagging. J Neurosci 30(14): 5118-5123.

42. Viola $H$, et al. (2000) Phosphorylated CAMP response element-binding protein as a molecular marker of memory processing in rat hippocampus: Effect of novelty. $J$ Neurosci 20(23):RC112.

43. Vianna MR, et al. (2000) Role of hippocampal signaling pathways in long-term memory formation of a nonassociative learning task in the rat. Learn Mem 7(5): 333-340. 
44. Alvares LO, Pasqualini Genro B, Diehl F, Molina VA, Quillfeldt JA (2008) Opposite action of hippocampal $\mathrm{CB} 1$ receptors in memory reconsolidation and extinction. Neurosci 154(4):1648-1655.

45. Izquierdo I, et al. (1998) Mechanisms for memory types differ. Nature 393(6686): 635-636.

46. Izquierdo I, Medina JH, Vianna MR, Izquierdo LA, Barros DM (1999) Separate mechanisms for short- and long-term memory. Behav Brain Res 103(1):1-11.

47. McGaugh JL (2000) Memory—a century of consolidation. Science 287(5451):248-251.

48. Kindler S, Kreienkamp HJ (2012) Dendritic mRNA targeting and translation. Adv Exp Med Biol 970:285-305.

49. Urbanska M, Gozdz A, Swiech LJ, Jaworski J (2012) Mammalian target of rapamycin complex 1 (mTORC1) and 2 (mTORC2) control the dendritic arbor morphology of hippocampal neurons. J Biol Chem 287(36):30240-30256.

50. Broadbent NJ, Gaskin S, Squire LR, Clark RE (2010) Object recognition memory and the rodent hippocampus. Learn Mem 17(1):5-11.
51. Izquierdo I, Myskiw JC (2011) Brain interactions between processes triggered by memory retrieval and their use in the treatment of fear memory. Future Neurol 6(3): 307-309.

52. Monfils MH, Cowansage KK, Klann E, LeDoux JE (2009) Extinction-reconsolidation boundaries: Key to persistent attenuation of fear memories. Science 324(5929):951-955.

53. Schiller D, et al. (2010) Preventing the return of fear in humans using reconsolidation update mechanisms. Nature 463(7277):49-53.

54. Davis M, Ressler K, Rothbaum BO, Richardson R (2006) Effects of D-cycloserine on extinction: Translation from preclinical to clinical work. Biol Psychiatry 60(4):369-375.

55. Paxinos G, Watson C (1986) The Rat Brain in Stereotaxic Coordinates (Academic, San Diego).

56. Izquierdo I, et al. (1997) Sequential role of hippocampus and amygdala, entorhinal cortex and parietal cortex in formation and retrieval of memory for inhibitory avoidance in rats. Eur J Neurosci 9(4):786-793.

57. Quirk GJ, Mueller D (2008) Neural mechanisms of extinction learning and retrieval. Neuropsychopharmacology 33(1):56-72. 